\title{
Understanding water challenges
}

\author{
Water research is expanding to better inform the management and policy decisions that are critical for
} a sustainable future.

G overnment officials, leaders in industry and non-government organizations, farmers, city planners and many other stakeholders are increasingly concerned about the current state of water resources, their future and the implications for our wellbeing. All of these interest groups are looking to academic research to identify better solutions to present challenges including water scarcity, pollution, and the governance of transboundary water resources, to name a few.

The number of international initiatives on water is telling. Over summer this year, two international meetings focusing on water - the Singapore International Water Week (8-12 July; www.siww.com.sg) and the World Water Week, organised by the Stockholm International Water Institute (26-31 August; www.siwi.org/publications/world-waterweek-programme-2018) - gathered together experts with the aim of finding new solutions to set societies on a path to sustainable water use. Another major meeting, the World Water Congress \& Exhibition, is organised by the International Water Association and will happen in Japan on 16-21 September (worldwatercongress.org). It will bring a strong engineering dimension to the debate. These high-profile events will bring together experts from a variety of backgrounds. Hopefully they will support efforts to improve our understanding of the challenges we face and efforts to find adequate solutions to water issues and their multiple environmental and socioeconomic ramifications, at different geographical and administrative scales.

As a matter of fact, water research is growing and at Nature Sustainability we are committed to tracking scholarly developments on various issues related to water resources and their human interface. In our April issue, Giam and colleagues (X. Giam et al. Nature Sustainability 1, 176-183; 2018) documented the impact of coal mining on stream biodiversity in the United States. The study quantifies the negative impacts of coal mining, under current federal statutes, on freshwater biota and shows that biodiversity impacts persisted even after post-mining reclamation. In addition to the significant environmental impacts of human activities, research has also shown the extent to which our societal demands for water resources might become increasingly difficult to meet over time. In our

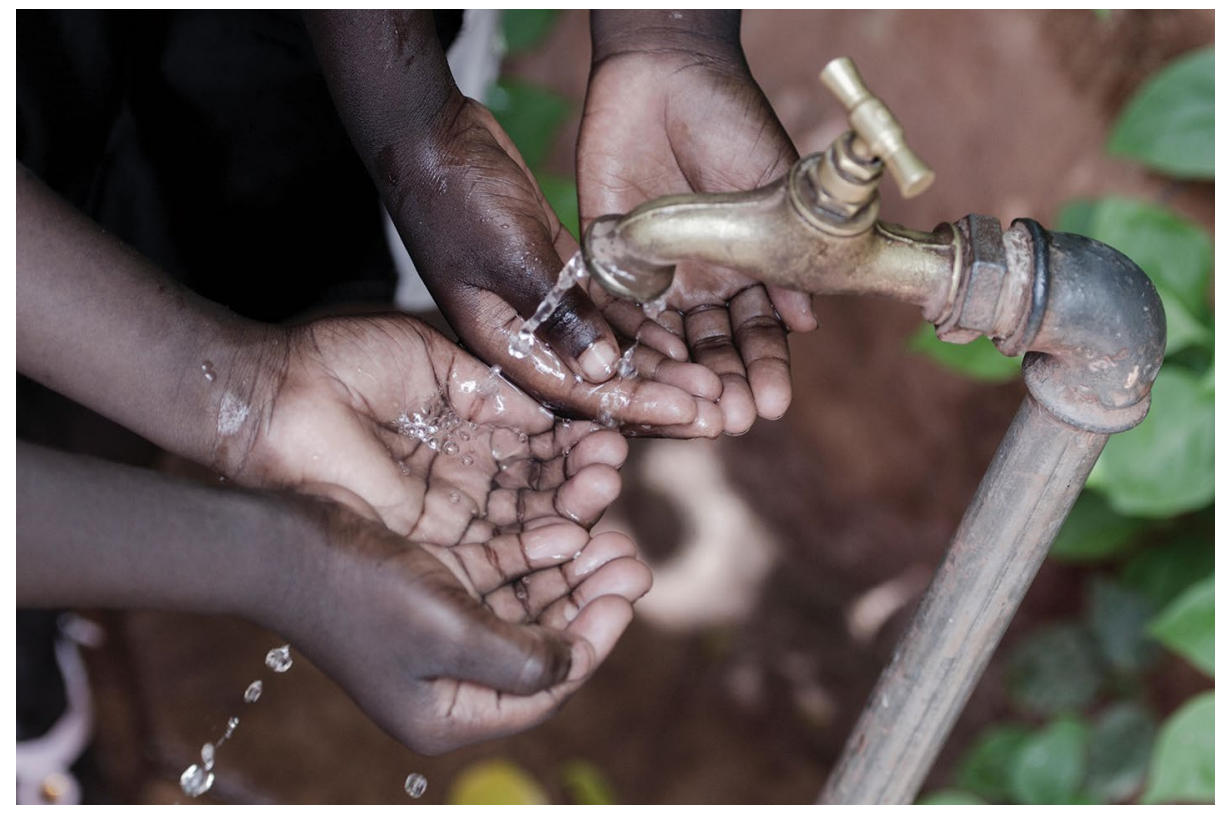

Credit: Riccardo Lennart Niels Mayer/Alamy Stock Photo

first issue, Flörke and co-authors (M. Flörke Nature Sustainability 1, 51-58; 2018) estimated that, factoring in both climate change and urban growth, more than $27 \%$ of the 482 cities considered in their analysis will have unmet water demands by 2050 , and an additional $19 \%$ of cities relying on surface-water transfers from other regions will likely experience water conflicts between urban and agricultural needs. These kinds of constraints explain the urgent need to improve the management of urban water resources, including implementing effective water-conservation strategies. In an Article published in our June issue, Porse and colleagues (E. Porse Nature Sustainability 1, 289-297; 2018) investigate Los Angeles county - an urban area in the United States characterized by seasonal dry weather and heavily reliant on imported water supplies from other parts of the state of California. They find that reducing water imports by increasing the use of local sources, including water re-use and conservation approaches, would be feasible and economically viable. Improving the management of water supplies alone will not suffice to achieve a sustainable water future. Efforts also have to go in the direction of lower consumption. In an Analysis by Vanham and colleagues, in this issue, the authors assess the water implications of shifting to healthier diets in the United Kingdom, Germany and France over the period 2007-2011. They perform their analysis on the smallest possible administrative regions within a country and find that generally, shifting to healthier diets reduces water use, particularly for healthy versions of pescatarian and vegetarian diets.

Academic research can also help managers to make effective decisions under uncertainty about the future of water resources. The Article by Greve et al. in this issue is an example of how scholarly work can support more robust approaches to decision-making, even in the presence of uncertainties in projected water scarcity.

There is more water-related research in our published pages, and more to come. And we hope to expand our coverage of water research soon, to include developments in other areas and topics. Our wish is to not only disseminate the latest advances to our broad audience, but also to reach out to those in a position to use such new knowledge to shape our water future.

Published online: 14 September 2018 https://doi.org/10.1038/s41893-018-0148-3 